\title{
MARIO DE ANDRADE E VICENTE HUIDOBRO: IDENTIDADES
}

\author{
Leonilda Arnbrozio \\ Universidade Fedoral do Paraná \\ RESUMO
}

Este ensaio faz uma comparaçăo entre os manifestos de Vicente Huidobro e Mário de Andrade, procurando mostrar as semelhanças de dois importantes movimentos literários da América: o "Creacionismo" e o Modernismo Brasileiro.

\section{PROPOSIÇAO}

Um destino semelhante no campo das letras norteou a vida de Mário de Andrade e Vicente Huidobro. Nascidos no fim do século passado - por coincidência, no mesmo ano (1893) - o poeta chileno e o brasileiro foram responsáveis por dois movimentos de significativa importância para a renovaçāo literária no inicio deste século. Mário foi a presença marcante do Modernismo Brasileiro. Com o Creacionismo", Vicente Huidobro revolucionou não só as letras chilenas como toda a literatura hispano-americana, colaborou para o desenvolvimento da vanguarda francesa e lançou a semente do Ultraismo espanhol.

Este ensaio pretende levantar os pontos de contacto e/ou divergências entre os dois poetas, através do estudo das proposições de arte poética contidas principalmente em seus manifestos. No caso de Mário, tomaremos por base o "Prefácio interessantíssimo" ", prefácio este que escreveu

1 Todas as citaçes do "Prefáclo interesscontissimo" e de "A eacrava que nåo Isaura" foram retiradas de TELEs. Gilberto Mendonca. Vanguarda europdia e modernismo brasileiro. Petrópolis. Vozes. 1977. 
para a sua Paulicéia desvairada, e "A escrava que não é Isaura", que é uma ampliação do primeiro. Para o estudo de Vicente Huidobro pesquisamos o prefácio ao livro de poemas Adán (1916), onde o poeta justifica as inovações que introduz na nova poética, o poema "Arte poética" (do livro El espejo de agua), que é um resumo da teoria do poeta e, evi. tentemente, os Manifestos (em número de treze) ", que $\dot{e}$ um livro essencialmente polèmico. Nele, além das propostas da "criaçāo pura", Huidobro critica o automatismo ditado pelo surrealismo e a apoteose da máquina cantada pelo Futurismo.

\section{O MODERNISMO E O "CREACIONISMO"}

Iodemos dizer que o emoriāo destes dois movimentos foi o ano de 1916. No decorrer da história da América é evidente a influência da Europa. No Brasil, por sua vez, muico mais que Portugal, nosso colonizador, a França sempre serviu como modelo. Na moda, nas regras de etiqueta, na literatura, sempre copiamos os rranceses. Uim fato, porém, decisivo em nossa História foi a Revolução Francesa, que inspirou os ideais democráticos $\epsilon$, com isso, não só a concretização dos ideais de independência do Brasil como da maioria dos paises da América. Ora, as idéias revolucionárias que fervilhavam na Europa no começo do século XX, nāo podiam passar despercebidas no Brasil. As idéias politicas eram consequiências do início da Primeira Guerra Mundial, a qual alcançava o seu auge em 1916. A renovação literária fazia-se necessária nesse mundo em crise. O Manifesto Futurista de Marinetti já em 1909 exaltava o mundo da máquina e da velocidade num verdadeiro canto à modernidade. Junto a essa temática, a forma curta, "rápida" do verso procurava transmitir o movimento, a dināmica, a velocidade que estavam ligados ao princípio estético que surgia: a simultaneidade. Apollinaire, no princípio do século: seria o precursor das novas tendências, explorando o aspecto visual dos poemas através de seus famosos Caligrammes e introduzindo na poética

2 Citamos por HUIDOBRo. Vicente. Obras pocticas setectas. Santiggo de Chlle. Ed. del Pactiftco. 1957. V. 1 
o insólito que viria substituir os temas e formas gastos do parnasianismo e do simbolismo.

No Brasil, o movimento que iria refletir a saturação dessas formas e a instatisfação da vanguarda brasileira seria o Modernismo. Tomando o ano de 1916 como gérmen desse movimento e o de 1945 como data do encerramento do ciclo modernista, o Professor Wilson Martins comenta:

Assim, o Modernismo foi, em grosso, o nosso "entre as duas guerras": nasceu do estado de espi- rito capitalizado pela Grande Guerra sobre a inquietação espiritual da primeira década do século, e desapareceu com o povo estado de consciência resultante da II Guerra Mundial, refletindo, em consequiência, um tipo particular de civilização artística e sendo, inicialmente, a manifestação brasileira dos 'roaring twenties", logo mais a expressão da inquietação política e afinal, nos seus últimos instantes, $o$ instrumento de retorno à literatura desinteressada. ${ }^{3}$

Indubitavelmente a Semana de Arte Moderna realizada em fevereiro de 1922 em São Paulo foi um acontecimento decisivo na história do movimento. Congregando a nova $\mathrm{e}$ atuante geração de músicos, escultores, pintores e literatos, ela seria, segundo Mário da Silva Brito *, o "coroamento" de um processo iniciado pela pintora Anita Malfatti em 1920. Ela seria também a própria conscientização do Modernismo. Vários manifestos apresentados durante a "Semana" e após ela ditavam as novas proposições do movimento. Muito mais que um movimento de revolução e renovação literárias, o Modernismo foi um apelo à liberdade criadora.

Mário de Andrade foi uma das maiores figuras desse movimento. justamente através dele que vemos o Modernismo evoluir, libertar-se do fantasma do Futurismo e tornar-se um movimento brasileiro. Em carta a Manuel Bandeira, diz:

3 Martins, Wilson. O Modernismo. Săo Paulo, Cultrix, 1973. p. 20

4 BRITO. Márlo da gllva. História do modernismo brasileiro; antececientes da Bemana de Arte Moderna. Bǿ Paulo, Baralva. 1958. y. 1. p. 185. 
Escrever arte moderna não significa jamais para mim representar a vida atual no que tem de exterior: automóveis, cinema, asfalto. Se estas palabras freqüentam o livro não é porque pense com elas escrever moderno, mas porque sendo mei li. vro moderno, elas têm sua razão de ser."

Em Vicente Huidobro observamos uma situação diferente à de Mário de Andrade. Enquanto este tomava conhecimento das vanguardas européias através de Oswald de Andrade, Huidobro vivi "in loco" esses movimentos. Ansiando horizontes mais largos, decide sua primeira viagem à Europa em 1916, ano marcadamente agitado por idéias revolu. cionárias no Velho Continente. No fim desse ano, confessa Huidobro, "cai en Paris en medio de la revista Sic", onde colaboravam Breton e Aragon e onde se publicavam os Caligrammes de Apollinaire.

Em 1917 funda com Reverdy a revista Nord-Sud, onde sob a paternidade de Appollinaire realizava as suas intenções estéticas, conquistando a simpatia dos franceses.

Tanto no caso do Modernismo como no do "Creacionismo" as idéias européias serviram somente como elemento de propulsāo. Mário muito cedo conscientizou-se da estagnacão do Futurismo. Quanto às idéias da criação absoluta, Huidobro já as tinha em 1912, isto é, muito antes de ir a Paris. Nessa época, faz uma declaração no número 5 dia revista Musa Joven: .

El reinado de la literatura terminó. El siglo veinte verá nacer el reinado de la poesia en el verdadero sentido de la palabra, es decir, en el de creación, como la llamaron los griegos, aunque jamás lo. graron realizar sua definición."

Nos anos subsequientes através de entrevistas, conferências e prefácios continua em sua proposição do "ato de criação" em oposição à poesia "alrededor de". Foi, porém, em uma conferência no Ateneo de Buenos Aires em junho de 
1916 que a denominação de "creacionista" ficou ligada para sempre ao nome do poeta. Aí ele afirmou que "la primera condición del poeta es crear, la segunda crear, y la tercera, crear". :

Em uma entrevista de 1919 ("Conversando con Huidobro"), Angel Cruchaga pergunta: "Qual é a estética do "Creacionismo?"

Queremos hacer un arte que no limite ni traduzca la realidad: deseamos elaborar un poema que to- mando de la vida sólo lo esencial, aquello de que no podemos prescindir, nos presente un conjunto lírico independiente que desprenda como resultado una emoción poética pura. (. . ) En mi modo de ver al "creacionismo" es la poesía misma: algo que no tiene por finalidad, ni narrar, ni describir las cosas de la vida, sino hacer una totalidad lírica independiente en absoluto. Es decir, ella misma es su propia finalidad. "

$\mathrm{O}$ que em realidade propunham estes dois grandes teorizadores era a ruptura da linguagem convencional, sentimental, acadêmica. Propuntıam a realidade da linguagem e não mais aquela ligada ao referencial. A literatura deixaria de ser uma fotografia, pois esta revela somente um exterior. Passaria a ser visão abrangente de uma realidae. Neste sentido, as proposições lançadas por Breton em seu Primeiro Manifesto (1924) viriam reforçar as idéias de Mário e de Huidobro.

\section{ARTE POETICA: COMPARAÇOES}

Para Octavio Paz a evolução da literatura brasileira e da hispano-americana realizou-se simultânea mas independentemente." Acrescenta ainda que, influenciados pelas mesnas enfermidades, descobridores das mesmas verdades, enamorados dos mesmos deuses", brasileiros e hispano-ameri-

7 IUIDOBRO. P. 267.

8 COsta, René de. Vicente Huidobro y el creacioniemo. Madrid, Taurus, 1975, p. 63.

o PAz. Octavlo. Poesla latino-amerlcana? In: - signos om rotacäo. Bso Paulo, Perepectiva, 1976. p. 145. 
canos continuaram incomunicados, cada qual vivendo a sua realidade. Para o crítico mexicano, o Modernismo Brasileiro "carece do radicalismo da vanguarda hispano-americana". Fato curioso é que Octavio Paz não cita Mário de Andrade. $E$ bem verdade que pelo titulo e substância de seu artigo: "Poesía latino-americana?" ele está referindo-se a Huidobropoeta. É também certo, por outro lado, que Mário foi mais teorizador que poeta: "Abandonei, traição consciente, a ficçāo, em favor de um homem-de-estudo que fundamentalmente não sou"." 1o

A incomunicabilidade entre a literatura brasileira e a hispano-americana é uma lamentável realidade, resultante da fronteira lingüistica, aparentemente transponivel. Segundo Paz, não há uma literatura argentina, cubana, etc., pois as tendências artisticas ultrapassaram as fronteiras políticas. Entretanto, diante do Brasil elas hesitam.

Mário de Andrade conhecia a teoria de Huidobro. Este conhecimento, porém, não se processou através da língua espanhola, mas da francesa, por meio da revista L'Esprit Nouveau. Aliás, Mário cita Huidobro em "A escrava que não é Isaura" quando se refere à criaçāo pura:

Mas essa inovação ( . . ) leva a conclusões e progressos. É por ela que o homem atingirá na futura perfeição de que somos apenas e modestamente os primitivos o ideal inegavelmente grandioso da "criação pura" de que fala Huidobro. (p. 245).

$O$ ato da criação pura foi uma verdadeira obsessão na vida literária do poeta chileno. Ele mesmo faz esta confissão em "La creación pura". Essa mesma preocupação norteará a arte poética de Mário. Nesse intento de criação estava implí. cito a oposição à função mimética da Arte. A natureza não deveria servir de cópia, mas de modelo no processo dessa criação:

El hombre nunca estuvo más cerca de la Natureza que ahora que ya no busca imitarla en sus apariencias, sino que hacer lo mismo que ella, imi- 
tándola en el plano de sus leyes constructivas, en la realización de un todo, en el mecanismo de la produccón de nuevas formas. ${ }^{11}$

Já em seu primeiro manifesto, significativamente chamado de "Non Serviam", o poeta passava de subjugado a senhor da natureza, num gesto de rebeldia e independência:

No he de ser tu esclavo, madre Natura; seré tu amo. Te servirás de mi; está bien. No quiero y no puedo evitarlo; pero yo también me serviré de ti. Yo tendré mis árboles que no serán como los tuyos, tendré mis montañas, tendré mis rios y mis mazes, tendré mi cielo y mis estrellas. ${ }^{12}$

Mário de Andrade segue a mesma linha de Huidobro em seus manifestos. Em seu "Prefácio interessantíssimo" aborda a diferença do belo da arte e do belo da natureza. Se o primeiro é arbitrário e convencional, se depende do ideal de beleza de uma época, ele nāo pode reproduzir o segundo que é imutável e objetivo. Em "A escrava que não é Isaura" fala do princípio de beleza da literatura "fin du siècle" e da nova tendência literária. A verdade da vida não é a mesma verdade da arte. Mário afirma: "O poeta não fotografa: cria. Ainda mais: não reproduz: exagera, deforma, porém sintetizando". (p. 246)

A fotografia pertence ao mundo objetivo, a criação ao subjetivo. A realidade do poema é uma realidade em si mes. ma, é um mundo erguendo-se por si mesmo, composto de imagens e conceitos criados pela subjetividade do poeta. Huidobro comenta seu verso: "El pájaro anida en el arco-íris", dizendo que essa realidade nunca ninguém viu, nem verá, mas que todos gostariam de ver.

Aparentemente não estão de acordo no que tange ao pa. pel do inconsciente na realização do poema. Enquanto Mário confessa: 
Quando sinto a impulsāo lirica escrevo sem pen. sar tudo o que meu inconsciente me grita.

(Prefácio interessantíssimo, p. 239).

Huidobro, criticando a escrita automática, afirma:

La poesia ha de ser creada por el poeta, con toda la fuerza de sus sentidos más despiertos que nunca. El poeta tiene un papel activo y no pasivo en la composición y el engranaje de su poema. ${ }^{13}$

Apesar do impulso lirico, Mário de Andrade com seu espírito crítico, volta para corrigir o que foi escrito:

Penso depois: não só para corrigir, como para justificar o que escrevi. Daí a razão deste Prefácio interessantíssimo. (p. 239).

Portanto, tanto Huidobro como Mário acreditam na necessidade do esforço consciente do poeta.

No que diz respeito ao verso, ele aparece como elemento precípuo na transmissão do estado lírico:

Que el verso sea como una llave

Que abra mil puertas."

Verso é o elemento da linguagem, que imita e or. ganiza o movimento do estado lírico.

( A escrava que nāo é Isaura, p. 245)

Ambos são adeptos do verso livre e isto é mais que natural para dois poetas que vivem a renovação da poesia. Má. rio diz que:

Continuar no verso medido é conservar-se na melodia quadrada e preferi-la à melodia infinita de que a música se utiliza sistematicamente desde a moda Wagner sem que ninguém a discuta mais.

(A escrava que não é Isaura p. 245) 
Huidobro, no prefácio de seu livro Adán (1916), nome rambém profundamente significativo pois nos lembra o processo da criação, justifica o emprego do verso livre neste poema:

Una vez concebida la idea de mi poema, la primera pregunta que me hice fue sobre el metro en que debia c'cuarrollarlo. Sin vacilar pensé en el verso libre, porque si hay un tema que exija esta nueva forma, ese tema es el mio, por su misma primitividad de vida libre. ${ }^{1 "}$

Quanto à métrica, Mário é menos radical. Embora nāo ache interessante o seu emprego, não faz nenhuma objeção que ela "aconteça" em seu poema: 'entram pois às vezes no cabaré rítmico dos meus verscs". (Prefäcio interessantíssimo).

Huidobro, entretanto, relaciona a métrica justamente ao que estão combatendo, isto é, o academicismo, a retórica:

Todos los metros oficiales me dan idea de cosa falsa, literaria, retórica pura. No les encuentro espontaneidad; me dan sabor a ropa hecha, a maquinaria bien aceitada, a convencionalismo. ${ }^{16}$

A visāo totalizadora da realidade poética fez com que o Modernismo Brasileiro e o "Creacionismo" abandonassem os temas poéticos. Tudo é possível dentro do mundo do artista. Para Mário:

A impulsão lírica é livre de nós, independe da nossa inteligência. Pode nascer de uma réstea de cebolas como de um amor perdido.

( A escrava que não é Isaura, p. 244)

Para Huidobro, o verdadeiro poeta transforma em poesia qualquer tema: 
Ser poeta consiste en tener una dosis tal de particular humanidad, que pueda conferirsele a todo lo que pase a través del organismo cierta electricidad atómica profunda, cierto calor nunca dado por otros a esas mismas palabras, cierto calor que hace cambiar de dimensión y color a las palabras.

\section{TRAVESSIA SEMELHANTE}

Papas de dois movimentos de vital importancia no clesenvolvimento de nossas letras, Mário e Huidobro seguiram uma travessia semelhante na instauração de uma nova poética. Realmente, no levantamento feito encontramos muito mais semelhanças que divergências. Essa identidade nāo está somente no nivel da teoria poética. Na criação literária também, E, nessa criaçāo, a renovação total da linguagem. Huidobro, num intento de conquistar uma linguagem - pois o "o espanhol é nosso e não é" - escreve em francês, para, num gesto simbólico, matar o espanhol castiço e americanizá-lo. Nessa busca da linguagem notamos a busca da própria identidade americana. Em Adán, "primera palabra, que hirió el silencio de la Tierra", o mito cosmogónico renasce do caos inicial para viver no universo do Novo Mundo. Seu extenso poema (Altazor) também é uma busca de si mesmo, da linguagem, do processo criativo.

Em Mário de Andrade essa busca da identidade brasileira se realiza através de Macunaíma onde o "herói sem nenhum caráter" engloba as três raças formadoras da sociedade brasileira. Procurando voltar-se para a realidade nacional, parte da linguagem falada (embora nāo reproduzida totalmente) para rebelar-se contra a linguagem acadêmica, ditada por Portugal. Veja-se "Cartas prás Icamiabas", em Macunaíma onde Mário parodia essa linguagem.

O nome de Mário, esse ainda grande desconhecido, ficará para sempre ligado às letras brasileiras como um simbolo de renovação e dedicação aos valores de sua terra.

A influência de Huidobro foi mais ampla que a de Mário, em virtude de suas inúmeras viagens. Participou dos mo- 
vimentos de vanguarda na França, revolucionou a literatura hispano-americana e, em sua estada na Espanha contribuiu para o desenvolvimento de outro movimento: o Ultraísmo.

A coincidência do ano de nascimento e à semelhança nos propósitos literários, acrescenta-se a quase coincidência no ano de morte (Mário - 1945; Huidobro - 1948).

\section{RESUMEN}

Este ensayo hace una comparación entre los manifes. tos de Vicente Huidobro y Mário de Andrade intentando mostrar las semejanzas de dos importantes movimientcs literarios de América: el Creacionismo y el Modernismo Brasileño.

\section{REFERENCIAS BIBLIOGRAFICAS}

1 BRITO, Mário da Silva. História do modernismo brasileiro; antecedentes da Semana de Arte Moderna. São Paulo, Saraiva, 1958. v. 1.

2 COSTA, René de. Vicente Huidobro y el creacionismo. Madrid, Taurus, 1975.

$?$ HUIDOBRO, Vicente. Obras poéticas selectas. Santiago de Chile, Ed. del Pacifico, 1957. v. 1.

4 MARTINS, Wilson. O modernlsmo. Sāo Paulo, Cultrix, 1973.

5 PAZ, Octavio. Signos em rotação. São Paulo, Perspectiva, 1976.

6 TELES, Gilberto Mendonça. Vanguarda européia e modernismo brasileiro. Petrópolis, Vozes, 1977. 